УДК 349.235

DOI https://doi.org/10.17308/vsu.proc.law.2021.1/3308

\title{
ПРАВОВОЕ РЕГУЛИРОВАНИЕ РЕЖИМА НЕНОРМИРОВАННОГО РАБОЧЕГО ВРЕМЕНИ: ПЛЮСЫ И МИНУСЫ
}

\author{
С. В. Передерин \\ Воронежский государственный университет \\ Поступила в редакцию 10 января 2021 г.
}

\begin{abstract}
Аннотация: расслатриваются понятие режима ненорлированного рабочего врелени, круг лии, на которых распространяется режил ненорлированного рабочего врелени. Исследуется порядок привлечения работников для работы в режиле ненорлированного рабочего дня, колпенсаиии за работу в режиме ненормированного рабочего дня. Выявляются основные положительные и отрицательные аспекты правового регулирования.

Ключевые слова: режил рабочего врелени, ненормированный рабочий день, работник, компенсаиии.
\end{abstract}

Abstract: considered the concept of the regime of irregular working time, the circle of persons who are the subject to the irregular working time. Investigated the order to attract workers to operate as irregular working time, compensation for work in the regime of irregular working time. The main positive and negative aspects of legal regulation are revealed.

Key words: working hours, irregular working time, worker, compensations.

В условиях существования рыночной экономики, когда господствующее положение в сфрере использования несамостоятельного труда за- нимают работодатели, радикального обновления и совершенствования 이 трудового законодательства, регулирующего трудовые и иные непосред2. ственно связанные с ними отношения в сфере применения наемного труда, возникает острая необходимость оптимального согласования интересов государства, работодателей и работников.

Актуальными становятся правовые проблемы защиты наемных работников, поскольку в современных условиях государство во главу угла ставит задачу всемерной поддержки работодателей, с целью усиления эффективности производства и создания на этой основе достойных условий жизнедеятельности граждан Российской Федерации. Работодатели, имея своих представителей в Государственной Думе РФ, путем соответствующих инициатив разрабатывают и принимают изменения и дополнения в действующий Трудовой кодекс Российской Федерации (далее - ТК РФ) в своих интересах, работники могут это сделать через своих представителей в лице профсоюзов, но это не всегда получается и занимает длительный период времени.

(C) Передерин С. В., 2021 
В связи с этим возникает необходимость переосмысления некоторых правовых положений, закрепленных в ТК РФ, которые были рассчитаны на их применение в условиях иного общественного строя. В частности, на наш взгляд, необходимо более четко сформулировать позицию законодателя относительно использования правового режима ненормированного рабочего времени, применяемого для отдельных категорий работников.

Правовые положения о регулировании труда работников с ненормированным рабочим днем были впервые закреплены в постановлении Народного комиссариата труда СССР от 13 февраля 1928 г. № 106 «O работниках с ненормированным рабочим днем» ${ }^{1}$, которые в определенной интерпретации были установлены и в действующем ТК РФ. То есть данное правовое положение без существенных изменений применяется почти сто лет. При этом следует отметить, что на протяжении всего периода применения ненормированного рабочего дня отсутствует четкий правовой механизм привлечения работников к выполнению своих трудовых (служебных) обязанностей в таком режиме.

Действующее трудовое законодательство предусматривает различные режимы рабочего времени: гибкий режим рабочего времени, сменный режим, режим разделения рабочего дня на части и ненормированный режим рабочего времени. Но если первые три вида режима рабочего времени применяются по соглашению сторон, то режим ненормированного рабочего времени применяется единолично работодателем (его правомочным представителем), т. е. без согласия работника, тем самым нарушается баланс интересов работника и работодателя.

Согласно ст. 97 ТК РФ работодатель имеет право привлекать работника к работе за пределами продолжительности рабочего времени, установленной для данного работника в соответствии с ТК РФ, другими федеральными законами и иными нормативными правовыми актами Российской Федерации, коллективным договором, соглашениями, локальными нормативными правовыми актами, трудовым договором для выполнения сверхурочной работы и работы на условиях ненормированного рабочего дня.

Сравнение правил проведения этих видов работ свидетельствует о следующем. Применительно к привлечению работников к сверхурочной работе установлен перечень (правда неисчерпывающий) оснований для привлечения к такой работе, определены общая и специальная правовые процедуры привлечения работников к сверхурочной работе, а также предельные сроки выполнения сверхурочной работы и альтернативный порядок компенсации (повышенной оплатой или предоставлением дополнительного времени отдыха не менее времени, отработанного сверхурочно).

Относительно применения ненормированного рабочего дня такой правовой механизм отсутствует. Законодателем не установлен перечень

\footnotetext{
${ }^{1}$ Известия НКТ СССР. 1928. № 9-10.
} 


\section{Вестник ВГУ. Серия: Право}

оснований привлечения работника за пределами установленной продолжительности рабочего времени для конкретного работника, отсутствуют правовые нормы, определяющие предельное число часов, отрабатываемых работником за пределами установленной для него нормы рабочего времени и другие правовые элементы.

Компенсация переработки рабочего времени при ненормированном рабочем дне допускается только предоставлением дополнительного оплачиваемого отпуска. Полагаем, что в условиях рыночной экономики это правовое положение не соответствует действительности.

Необходимо отметить, что правоприменительная и судебная практика не признают работу, выполняемую работником за пределами установленной продолжительности рабочего времени для конкретного работника, сверхурочной. Возникает вопрос: как же называется такая работа? Поскольку привлечение работника к работе за пределами установленного рабочего времени производится по инициативе работодателя путем издания приказа или распоряжения.

Налицо имеет место двойной стандарт. В одном случае одна и та же работа считается сверхурочной, а в другом - такой не считается.

В научной литературе по трудовому праву существуют две точки зрения относительно использования режима ненормированного рабочего дня.

Одни ученые полагают, что применение ненормированного рабочего дня вполне оправданно в условиях существования рыночной экономики, поскольку его использование необходимо для обеспечения нормального производственного процесса и организации несамостоятельного труда ${ }^{2}$. Другие полагают, что использование такого режима труда является латентной формой принудительного труда, поскольку позволяет работодателям практически безнаказанно привлекать работников к работе за пределами нормальной продолжительности рабочего времени неограниченное количество раз ${ }^{3}$. Полагаем, что использование режима ненормированного рабочего дня возможно и целесообразно лишь в том случае, когда будет разработан четкий правовой механизм его реализации с установлением юридических гарантий для работника.

Легальное определение ненормированного рабочего дня дается в

72 ст. 101 ТК РФ. Ненормированный рабочий день - особый режим работы, в соответствии с которым отдельные работники могут по распоряжению работодателя при необходимости эпизодически привлекаться к выполнению своих трудовых фрункций за пределами установленной для них

${ }^{2}$ См.: Костян И. А., Бережнов А. А. Ненормированный рабочий день : вопросы реформирования трудового законодательства // Трудовое право в России и за рубежом. 2018. № 1. С. 46 ; Трудовое право : опыт сравнительного правового исследования / В. М. Лебедев [и др.]. М., 2018. С. 371.

${ }^{3}$ См.: Белицкая И. Я. Особенности правового регулирования работы за пределами установленной продолжительности рабочего времени. М., 2013. С. 93 ; Щербакова С. И. Ненормированный рабочий день - теория и практика // Трудовое право. 2019. № 5. С. 28. 
продолжительности рабочего времени. Относительно данного правового определения ненормированного рабочего дня можно сделать следующие замечания.

Во-первых, оно содержит довольно общие и оценочные понятия, которые могут по-разному толковаться работодателями. Например, каких работников нельзя относить к лицам, выполняющим в режиме ненормированного рабочего (служебного) дня? Что следует понимать под эпизодическим привлечением работника к выполнению своей трудовой функции?

Во-вторых, в правоприменительной практике нередко имеют место случаи, когда работники, работающие в режиме ненормированного рабочего дня, в силу сознательности и понимания того, что необходимо завершить начатую работу, самостоятельно принимают решение о работе за пределами установленной для них продолжительности рабочего времени. Поэтому следует согласиться с предложением, высказанным учеными-трудовиками о законодательном определении ненормированного рабочего дня как особого режима, когда работник по собственному усмотрению, под контролем работодателя может остаться на своем рабочем месте и выполнять работу, которую он не успел закончить в урочное число часов в пределах установленной для него продолжительности рабочего времени ${ }^{4}$.

На основе анализа правовых положений, закрепленных в данной статье, можно сделать следующие выводы и предложения.

Из содержания ст. 101 ТК РФ не ясно, в какой форме (письменной или устной) должно даваться распоряжение работодателя (его правомочного представителя) о привлечении работника к работе за пределами установленной для него продолжительности рабочего времени. Полагаем, что оно должно издаваться в письменной фрорме, поскольку только при наличии такого распоряжения можно реально вести учет времени, фактически отработанного каждым работником, работающим в режиме ненормированного рабочего дня.

Работник, которому установлен ненормированный рабочий день, может привлекаться к выполнению своих трудовых (служебных) обязанностей как до начала рабочего дня (смены), так и после ее окончания, на него распространяются правила, определяющие время начала и окончания работы ${ }^{5}$.

Условие о работе в режиме ненормированного рабочего дня должно быть обязательно зафиксировано в содержании трудового договора, заключаемого с работником.

Привлечение работника (сотрудника) к работе в режиме ненормированного рабочего (служебного) дня возможно при одновременном нали-

${ }^{4}$ См.: Лебедев В. М., Мельникова В. Г., Назлетдинов Р. Р. Трудовое право : опыт сравнительного правового исследования. М., 2018. С. 395.

${ }^{5}$ Письмо Минтруда России от 29 октября 2018. № 14-2/00Г-8616. Доступ из справ.-правовой системы «КонсультантПлюс». 


\section{Вестник ВГУ. Серия: Право}

чии следующих условий: а) должность, на которую принимается работник (сотрудник), закреплена в специальном перечне должностей работников (сотрудников) с ненормированным рабочим днем, утвержденном работодателем (его правомочным представителем) с учетом мнения представительного органа работников; б) в содержании трудового договора должно быть зафиксировано условие о том, что работнику установлен ненормированный рабочий день; в) в содержании трудового договора зафиксировано положение о том, что работник будет выполнять конкретную трудовую функцию, а не дополнительные работы, относящиеся к работе с ненормированным рабочим (служебным) днем.

Режим ненормированного рабочего дня предполагает возможность переработки работником в отдельные рабочие дни (смены) рабочего времени, установленного для него. Но данное условие не является обязательным. При этом следует иметь в виду, что возможность переработки обусловлена обычным выполнением трудовых обязанностей, которые не были по каким-либо причинам выполнены в установленное для работника рабочее время, а не какими-либо экстраординарными обстоятельствами (аварией, стихийным бедствием и т. п.).

Работники, выполняющие свою трудовую функцию в режиме ненормированного рабочего дня, наравне со всеми другими работниками реализуют право на использование различных видов времени отдыха (междусменный отдых, выходные и нерабочие праздничные дни, ежегодный оплачиваемый отпуск и т. п.). В указанные периоды отдыха работники могут привлекаться к работе только с соблюдением общих правил и правовых процедур привлечения работников к работе в соответствующие периоды с предоставлением предусмотренных трудовым законодательством юридических гарантий и компенсаций.

Работник с ненормированным рабочим днем может привлекаться к выполнению трудовых (служебных) обязанностей за пределами установленной продолжительности рабочего времени только в соответствии с трудовой фрункцией. Если ему поручается работа, не обусловленная его трудовой функцией, то она должна быть произведена только с согласия работника и компенсирована на основе отдельного соглашения, заклю-

74 чаемого между работником и работодателем.

Правовой режим ненормированного рабочего дня распространяется не на всех работников, а только на определенные категории работников, установленные трудовым законодательством и иными нормативными правовыми актами, содержащими нормы трудового права.

В соответствии с действующим законодательством о труде ненормированный рабочий день может устанавливаться следующим категориям работников: 1) выполняющим административно-управленческие функции, технические и хозяйственные фрункции (руководителям организаций, их заместителям, главным бухгалтерам, руководителям фрилиалов, представительств и других обособленных структурных подразделений, главных и ведущих специалистов и т. п.); 2) труд которых в течение рабо- 
чего дня не поддается точному учету. $\mathcal{K}$ ним, в частности, относятся: консультанты, помощники, инструкторы, секретари, редеренты, советники и другие работники; 3) которые распределяют рабочее время по своему усмотрению. $\mathcal{K}$ ним относятся: менеджеры и сервисные инженеры по продажам, дистанционные работники, творческие работники, лесообъездчики, рекламные агенты, распространители билетов различных видов и др.; 4) рабочее время которых по характеру работы делится на части неопределенной продолжительности. К ним относятся работники, работающие в организациях, обслуживающих население (торговле, транспорте, сельском хозяйстве).

Согласно п. 3 ст. 45 Федерального закона от 27 июля 2004 г. № 79Ф3 (с изм. и доп.) «О государственной гражданской службе Российской Федерации» ${ }^{6}$ ненормированный служебный день устанавливается в обязательном порядке для гражданских служащих, замещающих высшие и главные должности гражданской службы, а для гражданских служащих, замещающих должности гражданской службы иных групп, ненормированный служебный день устанавливается в соответствии со служебным распорядком государственного органа по соответствующему перечню должностей и служебным контрактом. Ненормированный режим рабочего (служебного) дня устанавливается подзаконными нормативными правовыми актами, принимаемыми фредеральными исполнительными органами власти (министерствами, ведомствами, комитетами, службами и т. п.) для широкого круга своих работников (служащих): главных, ведущих и иных специалистов и сотрудников. Так, приказом МВД России от 1 фревраля 2018 г. № 50 «Об утверждении Порядка организации прохождения службы в органах внутренних дел Российской Федерации» ${ }^{7}$ утвержден перечень должностей в органах внутренних дел Российской Федерации, при замещении которых сотрудникам органов внутренних дел Российской Федерации может устанавливаться ненормированный рабочий день, аналогичные перечни утверждены для сотрудников органов принудительного исполнения и иных правоохранительных органов, а также сотрудников иных фредеральных исполнительных органов (спорта, науки и высшего образования, Роспотребнадзора и др.).

Приказом Минтранса России от 16 октября 2020 г. № 424 «Об утверждении особенностей режима рабочего времени и времени отдыха, условий труда водителей автомобилей» ${ }^{8}$ предусмотрен ненормированный рабочий день для водителей легковых автомобилей (кроме легковых такси), а также для водителей автомобилей, занятых на геологоразведочных, топографо-геодезических и изыскательских работах в полевых условиях.

Правовое регулирование труда работников, выполняющих свои трудовые фрункции в режиме ненормированного рабочего времени, нужда-

\footnotetext{
${ }^{6}$ Собр. законодательства Рос. Федерации. 2004. № 31. Ст. 3215.

7 Доступ из справ.-правовой системы «КонсультантПлюс».

8 Доступ из справ.-правовой системы «КонсультантПлюс».
} 


\section{Вестник ВГУ. Серия: Право}

ется в серьезном теоретическом переосмыслении и реформировании в условиях существования рыночной экономики и наличия массовой безработицы.

Таким образом, правовое понятие «отдельные работники», закрепленное в трудовом законодательстве, подразумевает значительное число лиц, работающих в режиме ненормированного рабочего (служебного) дня. К таким работникам относятся: сотрудники аппарата федеральных органов исполнительной власти, аппарата исполнительных органов субъектов РФ, муниципальных органов, правоохранительных органов, административно-управленческого персонала работодателей - юридических лиц и др.

Перечень должностей работников с ненормированным рабочим днем устанавливается коллективным договором, соглашениями или локальным нормативным актом, принимаемым работодателем с учетом мнения представительного органа работников. Наличие такого правового положения закрепляет возможность произвола со стороны работодателя, поскольку предоставляет ему право в любое время и на любой срок привлекать работника к выполнению закрепленной в трудовом договоре трудовой фрункции за пределами установленной для него продолжительности рабочего времени. При этом у работника, как правило, отсутствует возможность оспорить соответствующее решение работодателя (его правомочного представителя), и многие работники вынуждены соглашаться работать на соответствующих условиях. То есть по своей сути применение ненормированного рабочего дня в современных условиях является узаконенной формой дискриминации.

При этом следует иметь в виду, что ТК РФ прямо не предусматривает ограничения по применению ненормированного рабочего дня.

Специальное правило применения ненормированного режима рабочего времени установлено только для работников, работающих неполное

이 рабочее время. Согласно ч. 2 ст. 101 ТК РФ для таких работников режим ненормированного рабочего дня может быть установлен только в тех случаях, когда работник, работающий в режиме неполной рабочей недели, хотя бы один день выполняет свои трудовые (служебные) обязанности в течение всего рабочего дня или смены.

76 Для гражданских служащих, замещающих должности гражданской службы, не относящиеся к высшим и главным должностям гражданской службы, ненормированный служебный день устанавливается в соответствии со служебным распорядком соответствующего государственного органа в соответствии с конкретным перечнем должностей или служебным контрактом.

Положительная роль режима ненормированного рабочего дня заключается в том, что он дает возможность работодателю дополнительно эксплуатировать работников с ненормированным рабочим днем, экономя на использовании их труда финансовые ресурсы и получая дополнительную прибыль, не привлекая к труду дополнительных работников.

В отношении работников плюсом является то, что они независимо от того, по какой причине привлекались к работе за пределами установлен- 
ной для них продолжительности рабочего времени, вместо дополнительной оплаты получают дополнительный оплачиваемый отпуск продолжительностью не менее трех календарных дней.

Отрицательные моменты режима ненормированного рабочего дня проявляются в следующем.

Привлечение работников к работе за пределами установленной законодательством, коллективным договором, соглашениями, локальными нормативными актами, трудовым договором, как правило, свидетельствует о недостатках и сбоях в организации использования несамостоятельного труда. Основная цель привлечения работников к выполнению их трудовых функций за пределами установленной для них продолжительности рабочего времени заключается в устранении допущенных недостатков в работе, выполнении работы, не выполненной в нормальное рабочее время в интересах работодателя.

Недостатки в работе могут быть обусловлены как объективными фракторами, например необходимостью выполнения неотложных работ по составлению дополнительной отчетности, так и субъективными причинами, желанием работника показать свою необходимость для работодателя и получить дополнительный оплачиваемый отпуск. То есть имеет место злоупотребление правом как со стороны работодателя, так и работника.

Действующее трудовое законодательство и иные нормативные правовые акты, содержащие нормы трудового права, не устанавливают четких и конкретных критериев, характеризующих содержание трудовых функций, условий труда либо особенности его организации, на основе которых можно отнести те или иные должности в перечень должностей работников с ненормированным рабочим днем.

В правоприменительной практике имеет место постоянная работа отдельных категорий работников в режиме ненормированного рабочего дня. Это правило относится к руководителям структурных подразделений, которые приходят на работу раньше и уходят позже, начальникам смен, которые должны прийти на работу пораньше, чтобы принять смену.

Во многих случаях работники с ненормированным рабочим днем вынуждены по распоряжению работодателя находиться на своем рабочем месте, пока их руководитель не уйдет с работы. Все это отрицательно отражается на работе и здоровье работника, его психологическом состоянии, семейных отношениях. Но в случае отказа ему грозят определенные трудности при исполнении трудовых обязанностей, обусловленные соответствующим субъективным отношением руководителя.

С учетом изложенного, на наш взгляд, в отношении ненормированного рабочего времени следует принять одно из двух решений.

Учитывая практику зарубежных стран, в трудовом законодательстве которых отсутствует легальное определение ненормированного рабочего дня и опосредованно применяется к руководителям организаций (фирм, компаний и т. п.), отменить режим ненормированного рабочего времени. 


\section{Вестник ВГУ. Серия: Право}

Однако принятие такого решения маловероятно, поскольку работодатели, которые выражают свою волю через своих представителей в Федеральном Собрании РФ, не позволят отменить такой режим, поскольку он для них выгоден. Свидетельством тому является отклонение от рассмотрения федеральных законов о ненормированном рабочем дне.

Поэтому более реалистичным является решение, связанное с разработкой процедурно-процессуального правового механизма реализации и использования режима ненормированного рабочего дня.

В правовом механизме реализации правовых положений, регламентирующих ненормированный рабочий день, следует закрепить следующие правовые элементы: привлечение работников, работающих в режиме ненормированного рабочего дня, за пределами установленной для них продолжительности рабочего времени, должно производиться работодателем только в письменной форме; установить (как это характерно для сверхурочных работ) предельное количество часов переработки за пределами установленной продолжительности рабочего времени, в случае превышения указанной нормы работу следует считать сверхурочной со всеми вытекающими отсюда последствиями, вместо правового оценочного термина «эпизодического привлечения работников» за пределами установленной продолжительности рабочего времени, которое не несет в своем содержании конкретики, установить предельное количество случаев привлечения к работе за пределами установленной продолжительности рабочего времени, например два-три раза в неделю, исходя из имеющихся обстоятельств; запретить привлечение работников на условиях ненормированного рабочего дня в выходные и нерабочие праздничные дни; на условиях ненормированного дня, т. е. привлекать их к таким работам с соблюдением правовых положений, закрепленных в

- ст. 113 и 153 ТК РФ; учитывая имеющуюся правоприменительную прак을 тику, установить дополнительную оплату труда работников с ненормированным рабочим днем, такая доплата должна производиться водителям автомобилей МЧС, пожарной охране, Федеральной службе безопасности и сотрудникам других министерств и ведомств. Межрегиональным отраслевым соглашением по алмазно-бриллиантовому комплексу Россий-

78 ской Федерации на 2019-2021 годы п. 3.2.3 при установлении ненормированного рабочего дня водителю устанавливается доплата в размере, определяемом локальным нормативным актом организации, а также предоставляется дополнительный оплачиваемый отпуск в соответствии с коллективным договором организации. Установить правило, согласно которому при систематическом привлечении работника к выполнению своей трудовой функции за пределами установленной продолжительности рабочего времени такая работа является сверхурочной; закрепить правовое положение, запрещающее работодателю привлекать работников с ненормированным рабочим днем к работе за пределами установленного рабочего времени, не относящейся к его трудовой функции; закрепить перечень работников, которым нельзя устанавливать ненормированный 
рабочий день; установить правило, согласно которому перечень работников с ненормированным рабочим днем устанавливается с учетом содержания трудовой функции, условий и организации труда.

Воронежский государственный университет

Передерин С. В., доктор юридических наук, заведующий кафедрой трудового права

E-mail: perederin@law.vsu.ru
Voronezh State University

Perederin S. V., Doctor of Legal Sciences, Head of the Labour Law Department

E-mail:perederin@law.vsu.ru 